\title{
Efficacy of Additional Intervention to the Specific Health Guidance in Japan: The Takahata GENKI Project
}

\author{
Nao Enomoto' \\ Sho Nakamura ${ }^{2-4}$ \\ Satoru Kanda ${ }^{3-5}$ \\ Hiroko Endo' \\ Emiko Yamada' \\ Sachiyo Kobayashi ${ }^{\prime}$ \\ Miki Kido' \\ Rina Inoue ${ }^{4}$ \\ Junko Shimakura ${ }^{6}$ \\ Hiroto Narimatsu ${ }^{2-4,7}$ \\ 'Section of Health and Longevity Service, \\ Takahata Town Office, Takahata, \\ Yamagata, Japan; ${ }^{2}$ Graduate School of \\ Health of Innovation, Kanagawa \\ University of Human Services, Kawasaki, \\ Kanagawa, Japan; ${ }^{3}$ Cancer Prevention and \\ Control Division, Kanagawa Cancer \\ Center Research Institute, Yokohama, \\ Kanagawa, Japan; ${ }^{4} \mathrm{CIKOP}$, Specified \\ Nonprofit Corporation, Yamagata, Japan; \\ ${ }^{5}$ Department of Clinical Oncology, \\ Yamagata University Faculty of Medicine, \\ Yamagata, Japan; ${ }^{6}$ Section of Welfare and \\ Child Service, Takahata Town Office, \\ Takahata, Yamagata, Japan; ${ }^{7}$ Department \\ of Genetic Medicine, Kanagawa Cancer \\ Center, Yokohama, Kanagawa, Japan
}

Correspondence: Hiroto Narimatsu

Cancer Prevention and Cancer Control

Division, Kanagawa Cancer Center

Research Institute, 2-3-2 Nakao, Asahi-ku,

Yokohama, Kanagawa, 24I-85I5, Japan

Tel $+8 \mathrm{I}-45-520-2222$

Fax +8I-45-520-2216

Email hiroto-narimatsu@umin.org
Purpose: A tailored approach to individual risk factors for developing lifestyle-related diseases would help induce behavioral changes toward intervention acceptability. The addition of preventive healthcare programs to nationwide specific health guidance in Japan is adapted in a given region.

Patients and Methods: We conducted a prospective parallel-group comparison study on 195 eligible residents from Takahata, Japan, with a high risk of lifestyle-related diseases from 2014 to 2017 to examine whether such an intervention could improve the body mass index (BMI) and estimated glomerular filtration rate (eGFR).

Results: Of the 195 enrolled residents, 117 were assigned to the control group and 78 to the intervention group. They were $\leq 65$ years old and had a BMI $\geq 25 \mathrm{~kg} / \mathrm{m}^{2}$ and an eGFR $\leq 90 \mathrm{~mL} / \mathrm{kg} / 1.73 \mathrm{~m}^{2}$. We conducted certain interventions for each group, including additional blood testing, regular health guidance, and specific health guidance. After one year, neither BMI (intervention: $26.7 \pm 2.17 \mathrm{~kg} / \mathrm{m}^{2}$ vs control: $27.3 \pm 2.12 \mathrm{~kg} / \mathrm{m}^{2}, \mathrm{p}=0.076$ ) nor eGFR (intervention: $72.2 \pm 11.1 \mathrm{~mL} / \mathrm{kg} / 1.73 \mathrm{~m}^{2}$ vs control: $73.1 \pm 10.5 \mathrm{~mL} / \mathrm{kg} / 1.73 \mathrm{~m}^{2}, \mathrm{p}=0.608$ ) differed significantly between groups. However, after three years, the BMI in the intervention group $\left(26.4 \pm 2.05 \mathrm{~kg} / \mathrm{m}^{2}\right)$ was significantly reduced compared to that in the control group $\left(27.4 \pm 2.26 \mathrm{~kg} / \mathrm{m}^{2} ; \mathrm{p}=0.005\right)$.

Conclusion: The additional interventions might have contributed to a reduction in metabolic syndrome.

Trial Registration: This study was registered in the UMIN-Clinical Trials Registry (ID:000013581). More information: https://upload.umin.ac.jp/cgi-open-bin/ctr_e/ctr_view. cgi?recptno=R000015868. The registration date was 31/03/2014.

Keywords: personalized preventive medicine, body mass index, estimated glomerular filtration rate, medical cost

\section{Introduction}

Epidemiological and clinical studies have demonstrated the effectiveness of preventive medical interventions, such as lifestyle improvements and drug treatments, in many aspects. These interventions effectively manage lifestyle-related diseases, especially hypertension, diabetes, dyslipidemia, and chronic kidney disease. Such interventions also help prevent disease exacerbation in such individuals as secondary prevention measures. $^{1-5}$ In Japan, specific health check-ups and health guidance became institutionalized in 2008 as universal measures for secondary prevention., ${ }^{1,6}$ Thus, all residents with public health insurance aged 40-74 years are eligible for 
specific health check-ups. First, their waist circumference and body mass index (BMI) are measured. If the values are above the reference range (waist circumference: $85 \mathrm{~cm}$ for men and $90 \mathrm{~cm}$ for women; BMI: $25 \mathrm{~kg} / \mathrm{m}^{2}$ for both sexes), they are further classified based on other factors. These factors include blood glucose levels, circulating lipid (triglycerides and high-density lipoprotein [HDL] cholesterol) levels, blood pressure, and smoking status. They are then provided with healthcare guidance (ie, proactive or motivational support) tailored to their classification. This classification aims to use limited medical resources effectively, reducing medical costs as a long-term goal. ${ }^{1,7}$ Furthermore, focusing on visceral fat, waist circumference was adopted as one of the criteria for classification. Waist circumference and metabolic syndrome are the two terms used to educate the public about the importance of preventing lifestyle-related diseases. ${ }^{1,2,8}$

Specific health check-ups and health guidance effectively prevent the onset and severity of lifestyle-related diseases. ${ }^{9}$ However, particular challenges, especially behavioral change, have also been identified. In some cases, the guidance does not work. ${ }^{1}$ The nationwide uniform guidance standards and methods might not be sufficient to encourage and maintain behavioral change. ${ }^{10}$

Therefore, to resolve these challenges and improve the effectiveness of the current specific health check-ups and health guidance, we hypothesized that a "tailored" approach to an individual's risk factors would be promising. Based on a preliminary pilot observational study in the region, we developed a preventive healthcare program suitable for the region. In this program, intensive interventions were conducted in high-risk groups in the region. Compared to other municipalities in Yamagata, people in the town of Takahata had a higher incidence of metabolic syndrome (personal communication from Takahata Town Office). Hence, it is imperative that interventions be implemented in this region compared to other municipalities.

Our present study aimed to increase the effectiveness of the specific health guidance by developing a new additional medical examination program tailored to the characteristics of a region located in the countryside with a high aging rate. Based on the results of the retrospective analysis conducted at Takahata, we identified the target population expected to gain the greatest benefit from our interventions. We conducted this study with more intensive, prospectively validated interventions, including personal guidance, to investigate the possibility of improving $\mathrm{BMI}$ and reducing medical costs in the long term.

\section{Patients and Methods}

\section{Study Design}

Takahata is in the south of Yamagata Prefecture, Japan. It had a population of 23,654 in 2018 , with $31.8 \%$ of residents aged $\geq 65$ years old. ${ }^{11}$ Before this research project, a pilot retrospective observational study was conducted, and the preliminary data obtained on specific health checkups and medical costs in Takahata were analyzed. The results suggested that individuals aged $\geq 65$ years with a $\mathrm{BMI} \geq 25 \mathrm{~kg} / \mathrm{m}^{2}$ and an estimated glomerular filtration rate (eGFR) $\leq 90 \mathrm{~mL} / \mathrm{kg} / 1.73 \mathrm{~m}^{2}$ were at the highest risk of metabolic syndrome. Therefore, for this high-risk group, medical costs were most probably reduced by additional preventive interventions. Based on these results, we conducted a prospective interventional study to verify if the use of health guidance could help reduce the BMI in this high-risk group undergoing specific health check-ups in Takahata.

We recruited residents in the high-risk group based on the results of health check-ups conducted in 2014 (baseline). Physical examination included body weight, height, blood pressure and waist circumference, and blood investigations included fasting blood glucose levels, hemoglobin A1c levels, triglycerides levels, and HDL cholesterol levels. We did not exclude the subjects who received pharmacological treatment before the start of the intervention. We then assigned them to either the intervention group (two districts) or the control group (four districts) depending on where they lived before making parallelgroup comparisons. We could not adopt a randomized trial design, which would have been preferable in this study, due to the local government's existing health checkup plan.

Participants in the control group received the conventional health care program according to the universal specific health guidance in Japan. ${ }^{1,9}$ The detailed information of specific health guidance has been described elsewhere. ${ }^{1,9}$ In brief, subjects included all individuals or their family members aged 40-74 years, and exams included questionnaires, physical examinations, waist circumference, height, weight, blood pressure, blood samples, and urinalyses. If their waist circumference and BMI were above the reference range (waist circumference: $85 \mathrm{~cm}$ for men and $90 \mathrm{~cm}$ for women; BMI: $25 \mathrm{~kg} / \mathrm{m}^{2}$ for both sexes), they were further classified based on other factors, as described in the guideline. ${ }^{1,9}$ The reference range of the waist circumstances was based on the 
universal specific health guidance in Japan according to the definition of metabolic syndrome. ${ }^{1,9}$ These factors include fasting blood glucose levels (cut-off value: $110 \mathrm{mg} / \mathrm{dL}$ ), hemoglobin A1c levels (cut-off value: $5.6 \%$ ), circulating lipid (triglycerides (cut-off value; $150 \mathrm{mg} / \mathrm{dL}$ ) and HDL cholesterol (cut-off value: $40 \mathrm{mg} /$ $\mathrm{dL}$ )) levels, blood pressure (cut-off value: $130 \mathrm{mmHg}$ for systolic pressure or $85 \mathrm{mmHg}$ for diastolic pressure) and smoking status. They were then provided with health guidance (ie, proactive or motivational support) tailored to their classification. The detailed information based on the "common universal program in Japan" is indicated in black font in Figure 1.

In the intervention group, we conducted the additional programs as follows. We provided informative, motivational, and proactive support interventions. The informative intervention involved providing participants with an initial individual consultation followed by group guidance at three months, and individual consultation with a doctor was provided as required or requested. We also conducted monthly physical exercise courses (optional; conducted even in non-intervention regions) and blood test/performance assessments at six months. The motivational intervention aimed to provide group guidance at three months and individual consultation with a doctor as required or as requested. Finally, the proactive support intervention involved conducting blood tests at six months. Detailed information about the type and frequency of the intervention is described in Figure 1.

We used the $t$-test to examine the difference between the two groups in terms of means of variables measured at baseline and measurements from 2015 to 2018. We also performed linear regression analysis using the changes in health check-up values and annual medical costs for 2015 and 2017 as objective variables and the presence or absence of interventions as the explanatory variable (Supplemental Table 1).

The primary endpoint was the rate of improvement in BMI after the intervention. Secondary endpoints included the program completion rate and data related to postintervention laboratory tests, lifestyles, disease onset,

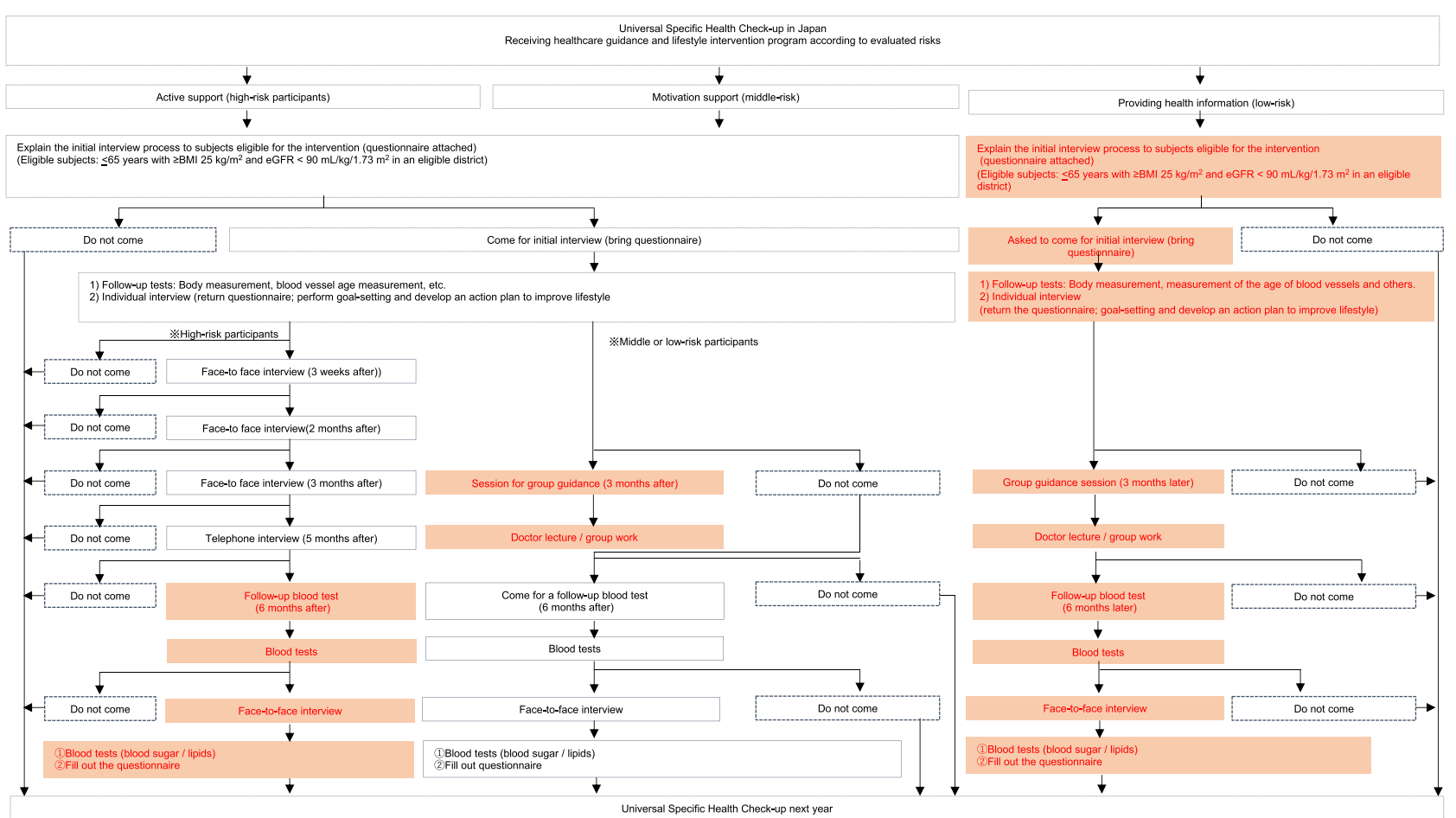

Figure I Intervention program. Black font indicates common universal program in Japan. Red font indicates additional intervention. In the common universal program, subjects with a waist circumference $\geq 85 \mathrm{~cm}$ (men) $/ \geq 90 \mathrm{~cm}$ (women) with at least two of the following:I impaired glucose tolerance (fasting blood glucose $\geq 100 \mathrm{mg} / \mathrm{dL}$ or hemoglobin Alc $\geq 5.6 \%$ ), 2 dyslipidemia (triglyceride $\geq 150 \mathrm{mg} / \mathrm{dL}$ or HDL-cholesterol $<40 \mathrm{mg} / \mathrm{dL}$ ), 3 high blood pressure (systolic blood pressure $\geq 130 \mathrm{~mm} \mathrm{Hg}$ or diastolic blood pressure $\geq 85 \mathrm{~mm} \mathrm{Hg}$ ) are considered at high risk. Subjects with a waist circumference $<85 \mathrm{~cm}$ (men) $/<90 \mathrm{~cm}$ (women) and body mass index $\geq 25 \mathrm{~kg} / \mathrm{m}^{2}$, with all of these three factor are also considered at high risk. The subjects at moderate risk comprise those with a waist circumference $\geq 85 \mathrm{~cm}$ (men)/ $\geq 90 \mathrm{~cm}$ (women) with one of the three risk factors or those with a waist circumference $<85 \mathrm{~cm}(\mathrm{men}) /<90 \mathrm{~cm}$ (women) a body mass index $\geq 25 \mathrm{~kg} / \mathrm{m}^{2}$ and having one or two of the three risk factors. The intervention did not include pharmacological treatment. 
death (ie, cause of death), and post-intervention annual medical costs. A sample size of 83 in each arm was calculated. Main cost of intervention is the additional labor costs of medical provider who supply the additional intervention; however, we did not calculate these exact costs.

This study was conducted in accordance with the Declaration of Helsinki. This study was conducted with written informed consent from the participants and the approval of the Institutional Review Board in Kanagawa Cancer Center (H27-Epidemiology 72) and Yamagata University School of Medicine (H26-183). This study was registered at the UMIN-Clinical Trials Registry (ID:000013581 https://upload.umin.ac.jp/cgi-open-bin /ctr e/ctr view.cgi?recptno=R000015868).

\section{Statistical Analysis}

Based on the data obtained from the pilot study, it was calculated that 83 people in one arm were needed to demonstrate a statistical difference in BMI, which was the primary endpoint of this study. We performed t-tests to compare endpoints, including BMI, eGFR, and medical cost between groups. Linear regression analysis was also conducted to evaluate endpoints using two distinct models. Model 1 included the groups, age, and sex. Model 2 included the groups, age, sex, and enrollment season.

The odds ratios (ORs) of the incidence of hypertension and dyslipidemia were determined by logistic regression analysis. We also analyzed four univariate models with efficiency scores as explanatory variables in two models and conventional risk factors in the other two. The first two models were adjusted for conventional risk factors, baseline age, sex, and baseline BMI. Statistical analyses were performed using EZR on $\mathrm{R}$ commander, version 1.4. ${ }^{12}$ For all analyses, statistical significance was established at $\mathrm{p}<0.05$.

\section{Results}

In this study, we recruited 195 patients, of whom 117 were assigned to the control group and 78 to the intervention group (Figure 2). The baseline characteristics of the participants are shown in Table 1. No significant difference was observed between the two groups. In the control group, three deaths were confirmed during the follow-up period.

The results of the interventions are presented in Figure 3. In total, 158 participants underwent health check-up 1 year later. Table 2 shows the comparative results of the changes in the health check-up values between the two groups. After one year, the change in BMI was not significantly different between groups (intervention: $26.7 \pm 2.17 \mathrm{~kg} / \mathrm{m}^{2}$ vs control: $27.3 \pm 2.12 \mathrm{~kg} / \mathrm{m}^{2}$, $\mathrm{p}=0.076$ ). Similarly, eGFR did not improve (intervention: $72.2 \pm 11.1 \mathrm{~mL} / \mathrm{kg} / 1.73 \mathrm{~m}^{2}$ vs control: $73.1 \pm 10.5 \mathrm{~mL} / \mathrm{kg} /$ $\left.1.73 \mathrm{~m}^{2}, \mathrm{p}=0.608\right)$. Of the 195 participants, 145 received follow-up survey in 2017. The baseline characteristics between the 145 participants and the remaining 50 participants was shown in Supplemental Table 2.

Three years later, in 2017, we re-examined 145 patients, including 86 in the control group and 59 in the intervention group. Table 2 compares the difference in BMI, eGFR, and medical costs between the two groups at different times (baseline and re-examination). BMI was significantly lower in the intervention group (intervention: $26.4 \pm 2.05 \mathrm{~kg} / \mathrm{m}^{2}$ vs control: $27.4 \pm 2.26 \mathrm{~kg} / \mathrm{m}^{2}, \mathrm{p}=$ 0.005). However, there was no significant improvement in eGFR ( $p=0.894)$. We also conducted multivariate analyses for clinical factors (Supplemental Table 1).

The average annual medical costs for the control and intervention groups in 1 year were $187,000 \pm 268,000$ yen and $185,000 \pm 261,000$ yen, respectively. The corresponding figures at 3 years were $284,000 \pm 355,000$ yen and $315,000 \pm 816,000$ yen, respectively. Our analyses show no significant difference between groups in terms of medical costs after three years $(p=0.78)$. Figure 4 shows the medical costs over time. At one year, the medical cost in the intervention group was higher than that in the control group. However, it was lower in the second, and especially in the third year.

\section{Discussion}

In this study, we conducted preventive medical interventions tailored to the individual risks of the local population. The primary aim of reducing BMI is expected to continue to improve in the intervention group. Although a significant difference did not emerge after one year of intervention, it was achieved after three years. Concentrated-effect interventions might have long-term benefits by curtailing lifestyle-related diseases that might affect older adults with less active daily activities. In this study, we speculated that individual guidance would be the first step in preventive medicine. It would help improve health behavior only among those provided with information at regular, specific health check-ups. Although research data are not available, we often observe ineffective interventions among those who repeatedly receive health guidance in the community. 


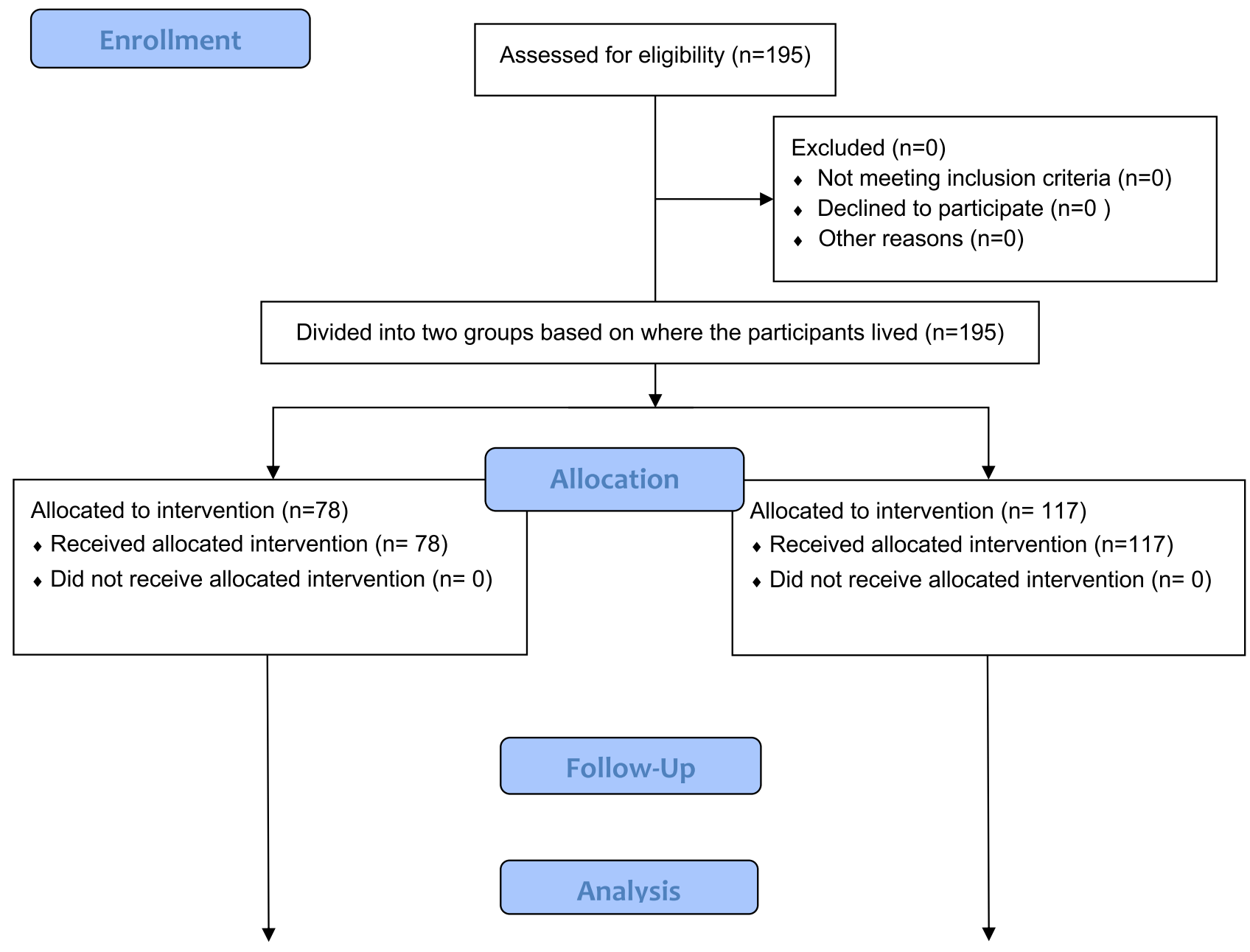

\section{Detailed follow-up and analysis data are shown in Figure 1}

Figure 2 CONSORT flowchart.

eGFR tended to decrease in both groups, which was probably due to aging, but showed no significant difference. Despite reductions in eGFR, the intervention did not

Table I Baseline Characteristics of Participants

\begin{tabular}{|l|c|c|c|}
\hline Characteristics & Intervention & Control & \multirow{2}{*}{ p value } \\
\cline { 2 - 3 } & $\mathbf{n = 7 8}$ & $\mathbf{n = I ~ I 7}$ & \\
\hline Age (years old) & $58.4 \pm 6.73$ & $59.0 \pm 5.47$ & 0.52 \\
Sex (male) & 45 & 69 & 0.88 \\
Systolic BP $(\mathrm{mmHg})$ & $132.6 \pm 15.5$ & $132.9 \pm 15.5$ & 0.91 \\
Diastolic BP $(\mathrm{mmHg})$ & $81.2 \pm 7.73$ & $81.3 \pm 9.11$ & 0.91 \\
BMI $\left(\mathrm{kg} / \mathrm{m}^{2}\right)$ & $27.0 \pm 2.12$ & $27.5 \pm 2.16$ & 0.09 \\
Cr $(\mathrm{mg} / \mathrm{dl})$ & $0.792 \pm 0.145$ & $0.799 \pm 0.129$ & 0.72 \\
eGFR $\left(\mathrm{mL} / \mathrm{kg} / \mathrm{I} .73 \mathrm{~m}^{2}\right)$ & $70.7 \pm 9.71$ & $69.6 \pm 8.99$ & 0.44 \\
\hline
\end{tabular}

Abbreviations: BP, indicates blood pressure; $\mathrm{BMI}$, body mass index; $\mathrm{Cr}$, creatinine; eGFR, estimated glomerular filtration rate. affect renal function. This might be because of several possible reasons. First, we did not conduct an intervention focused on reducing salt intake. Second, if eGFR reflected the effects of atherosclerosis, ${ }^{13,14}$ it would take more than BMI to achieve such results. Third, it might have been challenging to change the eating behavior of individuals with high salt intake.

It is noteworthy how medical costs changed over time. Our analysis showed that intervention might reduce medical costs in the long term. Initially, medical costs were higher in the intervention group. After three years, the control group had higher medical costs, but this was not statistically significant. This might be explained by the short-term increase in medical expenses due to the provision of consultations for those who needed treatment after health check-up. In the long term, medical costs might 


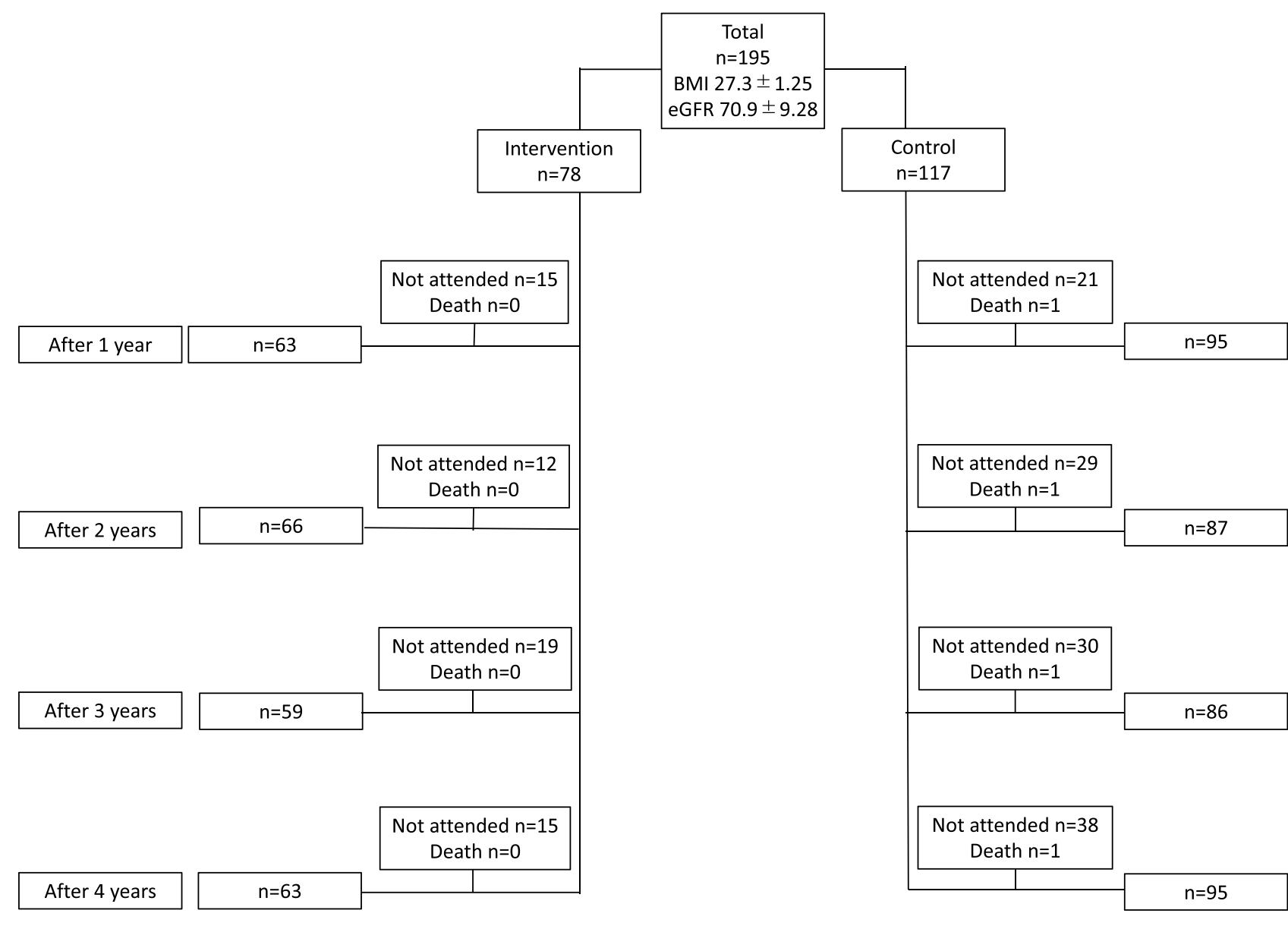

Figure 3 Follow-up flowchart of the participants.

Abbreviations: BMI, body mass index; eGFR, estimated glomerular filtration rate.

have decreased in line with the low demand for costly medical services or medications. Our study did not examine medical costs as a primary endpoint, nor did it have a large enough sample size to enable such statistical analysis. A large-scale study would, therefore, be required to verify this study's results.

This study provides valuable findings on the effectiveness of preventive care interventions tailored to the characteristics of the local population. Despite this, it has some limitations that need to be addressed. First, the effects of variations at the time of enrollment could not be ruled out. Second, this study had a small sample size, preventing the attainment of sufficient statistical power. Large-scale studies with better randomization schemes are required to validate these results. Third, the effect of drop-out might be underestimated. For example, a change in the average eGFR might not be due to improvements in individual participants but due to the drop-out of participants with the lowest eGFR. Future studies will allow for proper interpretation. Fourth, hip circumference has also been established as an important and independent determinant of cardiometabolic diseases. However, we could not include this parameter according to the universal guideline in Japan. Thus, it can be included in future studies. ${ }^{15}$ Fifth, socioeconomic status is reported to be related to the people's health status in Japan. ${ }^{16}$ This information was not included in the current study. The effect of this parameter on preventive medicine should be evaluated in future studies. Sixth, the main cost of the intervention was the additional labor costs for the medical provider who provided the additional intervention; however, we did not calculate the exact costs. Finally, the intervention itself requires further refinement. As a public health intervention, it needs to be developed at a low cost and as a sustainable program for residents.

\section{Conclusion}

In conclusion, our interventions led to a decrease in BMI at three years. It is considered that this contributed to a reduction in the prevalence of metabolic syndrome, which was the original purpose of the medical examination. The intervention also facilitated a long-term reduction in 
Table 2 Endpoints Between Intervention and Control Groups in 2015-2018

\begin{tabular}{|c|c|c|c|}
\hline & Intervention & Control & $\mathrm{p}$ value \\
\hline 2015 & $n=63$ & $\mathrm{n}=95$ & \\
\hline Waist circumference $(\mathrm{cm})$ & $89.6 \pm 5.97$ & $90.3 \pm 5.85$ & 0.48 \\
\hline $\operatorname{BMI}\left(\mathrm{kg} / \mathrm{m}^{2}\right)$ & $26.7 \pm 2.17$ & $27.3 \pm 2.12$ & 0.08 \\
\hline $\mathrm{sBP}(\mathrm{mmHg})$ & $133 \pm 17.8$ & $136 \pm 18.1$ & 0.31 \\
\hline $\mathrm{dBP}(\mathrm{mmHg})$ & $81.2 \pm 8.81$ & $81.7 \pm 10.8$ & 0.73 \\
\hline eGFR $\left(\mathrm{mL} / \mathrm{kg} / 1.73 \mathrm{~m}^{2}\right)$ & $72.2 \pm 11.1$ & $73.1 \pm 10.5$ & 0.61 \\
\hline Triglycerides (mg/dL) & $149 \pm 95.8$ & $140 \pm 90.7$ & 0.56 \\
\hline LDL-cholesterol (mg/dL) & $128 \pm 26.9$ & $118 \pm 32.7$ & 0.05 \\
\hline HDL-cholesterol (mg/dL) & $54.0 \pm 11.3$ & $54.6 \pm 13.1$ & 0.79 \\
\hline $\mathrm{FBG}(\mathrm{mg} / \mathrm{dL})$ & $107 \pm 23.7$ & $103 \pm 16.2$ & 0.21 \\
\hline Hemoglobin Alc (\%) & $6.11 \pm 0.78$ & $6.03 \pm 0.83$ & 0.55 \\
\hline Medical Cost $\left(\times 10^{3} \mathrm{JPY}\right)$ & $187 \pm 268$ & $|85 \pm 26|$ & 0.95 \\
\hline 2016 & $n=66$ & $n=87$ & \\
\hline Waist circumference $(\mathrm{cm})$ & $89.9 \pm 5.76$ & $90.8 \pm 6.16$ & 0.34 \\
\hline BMI (kg/m2) & $26.6 \pm 2.09$ & $27.1 \pm 2.05$ & 0.13 \\
\hline $\mathrm{sBP}(\mathrm{mmHg})$ & $134 \pm 16.4$ & $136 \pm 18.1$ & 0.60 \\
\hline $\mathrm{dBP}(\mathrm{mmHg})$ & $81.0 \pm 8.92$ & $81.1 \pm 10.8$ & 0.98 \\
\hline eGFR $\left(\mathrm{mL} / \mathrm{kg} / 1.73 \mathrm{~m}^{2}\right)$ & $71.2 \pm 10.1$ & $72.0 \pm 11.5$ & 0.66 \\
\hline Triglycerides (mg/dL) & $128 \pm 55.7$ & $134 \pm 92.7$ & 0.65 \\
\hline LDL-cholesterol (mg/dL) & $127 \pm 27.3$ & $118 \pm 33.5$ & 0.10 \\
\hline HDL-cholesterol (mg/dL) & $54.7 \pm 10.8$ & $54.5 \pm 12.3$ & 0.93 \\
\hline $\mathrm{FBG}(\mathrm{mg} / \mathrm{dL})$ & $105 \pm 19.1$ & $104 \pm 13.8$ & 0.71 \\
\hline Hemoglobin AIc (\%) & $6.12 \pm 0.64$ & $6.01 \pm 0.47$ & 0.20 \\
\hline Medical Cost $\left(\times 10^{3} \mathrm{JPY}\right)$ & $260 \pm 384$ & $242 \pm 275$ & 0.74 \\
\hline 2017 & $n=59$ & $n=86$ & \\
\hline Waist circumference $(\mathrm{cm})$ & $89.5 \pm 6.27$ & $91.5 \pm 6.54$ & 0.07 \\
\hline BMI (kg/m2) & $26.4 \pm 2.05$ & $27.4 \pm 2.26$ & 0.01 \\
\hline $\mathrm{sBP}(\mathrm{mmHg})$ & $136 \pm 16.3$ & $136 \pm 18.8$ & 0.98 \\
\hline $\mathrm{dBP}(\mathrm{mmHg})$ & $81.3 \pm 8.96$ & $80.5 \pm 13.1$ & 0.69 \\
\hline eGFR $\left(\mathrm{mL} / \mathrm{kg} / \mathrm{l} .73 \mathrm{~m}^{2}\right)$ & $71.1 \pm 9.80$ & $71.3 \pm 10.4$ & 0.89 \\
\hline Triglycerides (mg/dL) & $133 \pm 64.2$ & $135 \pm 88.4$ & 0.87 \\
\hline LDL-cholesterol (mg/dL) & $126 \pm 29.0$ & $118 \pm 28.9$ & 0.11 \\
\hline HDL-cholesterol (mg/dL) & $56.6 \pm 11.7$ & $55.7 \pm 13.3$ & 0.67 \\
\hline FBG $(\mathrm{mg} / \mathrm{dL})$ & $111 \pm 29.6$ & $107 \pm 14.6$ & 0.33 \\
\hline Hemoglobin Alc (\%) & $6.16 \pm 0.99$ & $6.02 \pm 0.49$ & 0.26 \\
\hline Medical Cost $\left(\times 10^{3} \mathrm{JPY}\right)$ & $284 \pm 355$ & $315 \pm 816$ & 0.78 \\
\hline 2018 & $n=63$ & $n=95$ & \\
\hline Waist circumference $(\mathrm{cm})$ & $91.5 \pm 7.06$ & $92.7 \pm 6.87$ & 0.30 \\
\hline BMI $(\mathrm{kg} / \mathrm{m} 2)$ & $26.7 \pm 2.20$ & $27.4 \pm 2.40$ & 0.07 \\
\hline $\mathrm{sBP}(\mathrm{mmHg})$ & $132 \pm 15.7$ & $132 \pm 13.0$ & 0.94 \\
\hline $\mathrm{dBP}(\mathrm{mmHg})$ & $81.8 \pm 9.33$ & $80.9 \pm 10.7$ & 0.59 \\
\hline eGFR $\left(\mathrm{mL} / \mathrm{kg} / \mathrm{l} .73 \mathrm{~m}^{2}\right)$ & $71.5 \pm 10.7$ & $71.3 \pm 11.0$ & 0.92 \\
\hline Triglycerides (mg/dL) & $130 \pm 62.5$ & $140 \pm 118$ & 0.54 \\
\hline LDL-cholesterol (mg/dL) & $120 \pm 28.9$ & $115 \pm 29.6$ & 0.30 \\
\hline HDL-cholesterol (mg/dL) & $55.0 \pm 12.5$ & $56.1 \pm 13.7$ & 0.61 \\
\hline $\mathrm{FBG}(\mathrm{mg} / \mathrm{dL})$ & $112 \pm 24.9$ & $107 \pm 15.4$ & 0.18 \\
\hline Hemoglobin Alc (\%) & $6.15 \pm 0.70$ & $5.99 \pm 0.50$ & 0.13 \\
\hline Medical Cost $\left(\times 10^{3} \mathrm{JPY}\right)$ & $256 \pm 314$ & $295 \pm 458$ & 0.56 \\
\hline
\end{tabular}

Abbreviations: BP, indicates blood pressure; BMI, body mass index; sBP, systolic blood pressure; dBP, diastolic blood pressure; eGFR, estimated glomerular filtration rate; FBG, fasting blood glucose. 
A

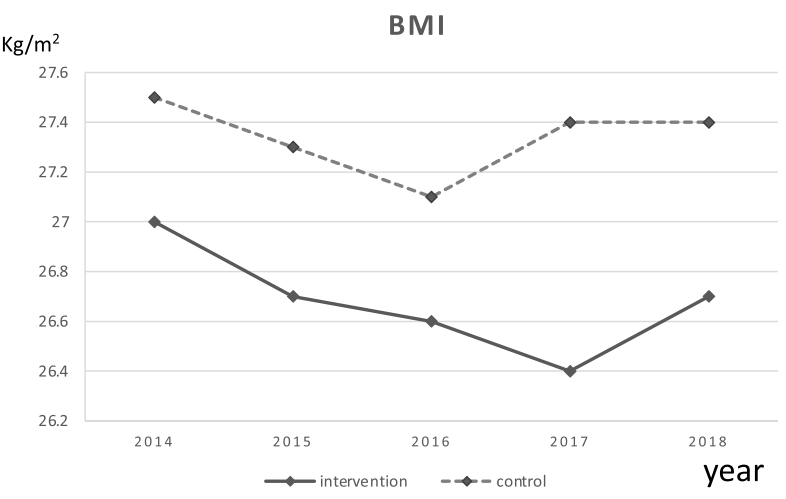

\section{C}

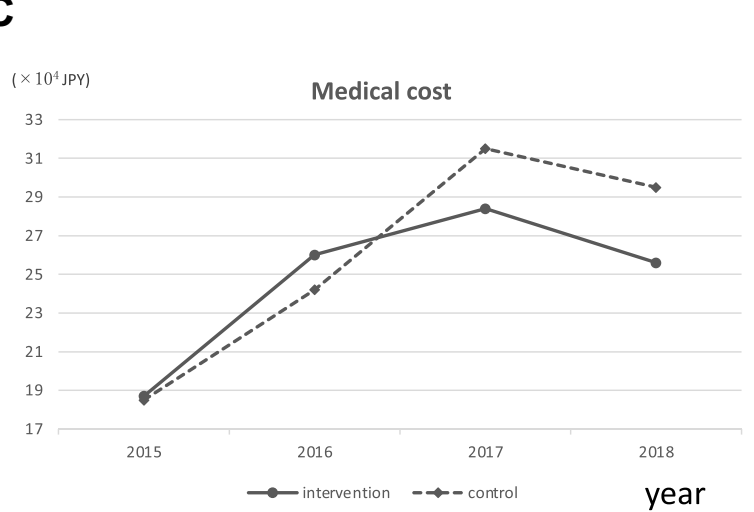

B

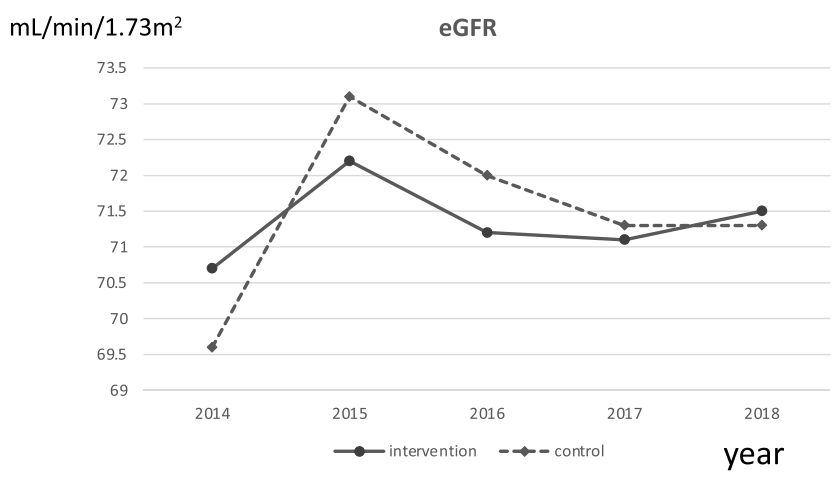

Figure 4 Trends of body mass index (BMI) (A), estimated glomerular filtration rate (eGFR) (B), and medical costs (C).

medical costs, suggesting that preventive medicine tailored to the regional context is effective.

\section{Acknowledgments}

This work was partly supported by the city of Takahata, Yamagata, Japan. We thank all the staff of Takahata city and Takahata Hospital, and CIKOP, Specified Nonprofit Corporation, for their support of this study. We would like to thank Editage for editing and reviewing this manuscript for English language.

\section{Disclosure}

The authors report no conflicts of interest in this work.

\section{References}

1. Tsushita K. Obesity: progress in diagnosis and treatment; Topics, I. Diagnosis and related examinations; 2. Specific health check-up and health counseling]. Nihon Naika Gakkai Zasshi. J Jpn Soc Intern Med. 2011;100(4):903-910.

2. Iso H, Sato S, Kitamura A, et al. Metabolic syndrome and the risk of ischemic heart disease and stroke among Japanese men and women. Stroke. 2007;38(6):1744-1751. doi:10.1161/STROKEAHA.106.469072
3. Kinoshita M, Yokote K, Arai H, et al. Japan atherosclerosis society (JAS) guidelines for prevention of atherosclerotic cardiovascular diseases 2017. $J$ Atheroscler Thromb. 2018;25(9):846-984. doi:10.5551/jat.GL2017

4. Nakata Y, Sasai H, Tsujimoto T, Hashimoto K, Kobayashi H. A single motivational lecture can promote modest weight loss: a randomized controlled trial. Obes Facts. 2020;13(2):267-278. doi: $10.1159 / 000506813$

5. Yonemoto K, Doi Y, Hata J, et al. Body mass index and stroke incidence in a Japanese community: the Hisayama study. Hypertens Res. 2011;34(2):274-279. doi:10.1038/hr.2010.220

6. Chei CL, Iso H, Yamagishi K, Inoue M, Tsugane S. Body mass index and weight change since 20 years of age and risk of coronary heart disease among Japanese: the Japan public health center-based study. Int J Obes (Lond). 2008;32(1):144-151. doi:10.1038/sj.ijo.0803686

7. Hiratsuka Y, Yamaki Y, Okamoto E, Tsubaki H, Kumakawa T. Relationships between medical expenditures and the specific health checkups scheme in Japan: A study of outpatient medical expenditures and questionnaire responses concerning lifestyle that form part of the specific health checkups scheme in Japan. J Natl Inst Public Health. 2017;66(66):75-84.

8. Eckel RH, Grundy SM, Zimmet PZ. The metabolic syndrome. Lancet. 2005;365(9468):1415-1428. doi:10.1016/S0140-6736(05)66378-7

9. Nakao YM, Miyamoto Y, Ueshima K, et al. Effectiveness of nationwide screening and lifestyle intervention for abdominal obesity and cardiometabolic risks in Japan: the metabolic syndrome and comprehensive lifestyle intervention study on nationwide database in Japan (MetS ACTION-J study). PLoS One. 2018;13(1):e190862. doi:10.1371/journal.pone.0190862 
10. Challenges in specific health checkups scheme in Japan (in Japanese). Cited April 8, 2019. Available from: https:/www.mhlw.go.jp/stf/shingi/ 2r9852000002d8ft-att/2r9852000002d8lv.pdf. Accessed September 8, 2020

11. Summary of Takahata in 2018. Cited April 8, 2019. Available from: https://www.town.takahata.yamagata.jp/material/files/group/2/20180710-1102.pdf. Accessed September 8, 2020.

12. Kanda Y. Investigation of the freely available easy-to-use software 'EZR' for medical statistics. Bone Marrow Transpl. 2013;48 (3):452-458. doi:10.1038/bmt.2012.244

13. Wu Z, Jiang Y, Jia J, et al. Metabolic syndrome is associated with rapid estimated glomerular filtration rate decline in a Chinese community-based population. Diabetes Metab Syndr Obes. 2019;12:2085-2093. doi:10.2147/DMSO.S217326
14. Ishizaka Y, Ishizaka N, Tani M, et al. Relationship between albuminuria, low eGFR, and carotid atherosclerosis in Japanese women. Kidney Blood Press Res. 2008;31(3):164-170. doi:10.1159/000131750

15. Stefan N. Causes, consequences, and treatment of metabolically unhealthy fat distribution. Lancet Diabetes Endocrinol. 2020;8 (7):616-627. doi:10.1016/S2213-8587(20)30110-8

16. Kagamimori S, Gaina A, Nasermoaddeli A. Socioeconomic status and health in the Japanese population. Soc Sci Med. 2009;68 (12):2152-2160. doi:10.1016/j.socscimed.2009.03.030

\section{Publish your work in this journal}

Risk Management and Healthcare Policy is an international, peerreviewed, open access journal focusing on all aspects of public health, policy, and preventative measures to promote good health and improve morbidity and mortality in the population. The journal welcomes submitted papers covering original research, basic science, clinical \& epidemiological studies, reviews and evaluations, guidelines, expert opinion and commentary, case reports and extended reports. The manuscript management system is completely online and includes a very quick and fair peer-review system, which is all easy to use. Visit http://www.dovepress.com/testimonials.php to read real quotes from published authors.

Submit your manuscript here: https://www.dovepress.com/risk-management-and-healthcare-policy-journal 